\title{
FROM THE INSIDE
}

\section{A few sick men in a golf car? Burned-out practitioners in a burned-out world}

\author{
Amr S. Omar ${ }^{1,2,3 *}$ (D), Dana Ibrahim ${ }^{4}$ and Mohamed Khali ${ }^{5}$
}

๑ 2021 Springer-Verlag GmbH Germany, part of Springer Nature

This is not a dystopian movie; a golf car with three sick patients on diverse respiratory support devices, going out for the first time after being hospitalized, accompanied by a nurse and a physiotherapist.

It was April 2021 in Doha; coronavirus disease 2019 (COVID-19) had peaked in a second wave and the health system had dictated a state of emergency that culminated in a second lockdown. Apart from healthcare sectors and food stores, daily routines had gone.

18 months since the first announcement of the pandemic, the expectation that vaccination and the waning of that first wave would return 'life as normal' slowly faded. The second and third waves hit hard.

In our hospital Hamad Medical Corporation, Doha, Qatar, a task force mobilized to co-ordinate critical and non-critical care physicians to the major casualty center of COVID-19. As cardiac intensivists, many of us were eager to help the suffering of COVID-19 patients and by extension, our colleagues. However, moving outside our comfort zone brought mixed feelings "I may get infected; I may carry infection to my family; I may not do a good job; moreover, I may cause harm rather than benefit". Most of these feelings vanished from the first minute I encountered the COVID-19 field hospital. The motives for accepting the responsibility to help in this mission blended human and ethical commitments, and even extended to religious and cultural motives.

So many memories are cemented into my head. A symptomatic man in his early 60 s who was not compliant with self-prone positioning and non-invasive mask ventilation. When I tried to convince him to follow the

*Correspondence: a_s_omar@yahoo.com

${ }^{1}$ Department of Cardiothoracic Surgery/Cardiac Anaesthesia \& ICU Section, Heart Hospital, Hamad Medical Corporation, 3050 Doha, Qatar

Full author information is available at the end of the article treatment, he disagreed, "Doctor, do you think you could tolerate this machines for 10 days?!". Subsequently his condition got worse, requiring intubation. I told him this was the only option left. He faced this dilemma bravely and made his last prayer with a mix of anxiousness and faith. Four hours later, he developed pneumomediastinum and extensive subcutaneous emphysema. Death came within days.

Another awake patient questioned, "please... every day you tell me that I am improving, then why am I not out of this place?". I kept reiterating the same lines; that he is slowly recovering, and he is on the right track. After 18 successive days of repeating these assuring words differently, a friendship of a kind formed between us. Finally, on day 18 , he became extremely tachypneic and desaturated. Therefore, I told him, "I must intubate you and put you on a machine to support your breathing, you are exhausted now, and nothing else is going to help". He replied that he was a migrant "I do not want to leave my family alone; they just moved here. It is not about me". Despite 25 years of experience, I found it difficult to persuade him to agree to an intervention when I was so unsure about the outcome. The patient asked, "How many days you will put me to sleep". I did not know, so I told him "Pray to God, you were suffering for many days, and it is time to have some rest". The term "kiss of death" referring to intubation, after being dormant for many years, was again resurfacing in my mind.

As an intensivist, I had often met situations at the time of intubation where patients were frustrated, but with COVID-19, we found them more pessimistic about the outcome of this intervention. There is no way to avoid patients' social and ethical dilemmas-complex issues, which reflected not only on patients but also on health caregivers [1]. Emotional exhaustion, depersonalization and lack of personal accomplishment are the cardinal manifestations of burnout. In one highly alarming study 
conducted recently in Ireland, the authors reported that three out of four physicians suffered from burnout during the pandemic [2].

The tragedy beyond this scene is indisputable; health care practitioners are exposed to significant risk, many of them have died and more deaths can be expected. In addition, the delayed and inconvenient governmental responses have added to fragmentation and tension in the health care system [3]. Four radical reasons were identified to cause burnout in the pandemic settings: the slowdown of routine medical care, the impact on vulnerable patient populations; limited resources and staffing; and the colossal workload demands [2]. There is insufficient data to suggest that any current organization-based approach of minimizing burnout among practitioners give meaningful benefits [4]. In our scenario, the tension was added to even more by having a team of mixed specialists, not all of whom were proficient in critical care.

However, these three 'sick' patients in the golf car were having an outing for the first time. Variable levels of oxygen supported their life and their eyes told of the resignation that lamented a world that had changed. They seemed to wonder if 'normal life' was out there, at all. However, these complex feelings were shared, by both patient and practitioner. They may have even hit the practitioners first. Under such conditions of uncertainty and stress-related anxiety, who knows what new breed of medical practitioners we were creating? Three sick patients and those staff were on a journey somewhere and who, really, knew where?

It is the legacy of this pandemic that the old patterns of critical care leadership to promote mental wellbeing cannot be carried out in the same way, because we are not the same. Schittek et al. mentioned that care of mental health within the critical car team should be scaffolded with resources, open discussions, satisfying basic needs, and promoting expression of problems to relieve the psychological tension of practitioners in the pandemic [5].

Stories like these ones, those vivid descriptions of poignant bedside moments have happened to us all and they should remind us of this salient point: that we need to do better to support the mental health of practitioners and to honor those narratives. We need to ensure, that wherever this golf car is taking us-it is taking us all, somewhere better.

\begin{abstract}
Author details
1 Department of Cardiothoracic Surgery/Cardiac Anaesthesia \& ICU Section, Heart Hospital, Hamad Medical Corporation, 3050 Doha, Qatar. ${ }^{2}$ Department of Critical Care Medicine, Beni Suef University, Beni Suef, Egypt. ${ }^{3}$ Weill Cornell Medical College-Qatar, Doha, Qatar. ${ }^{4}$ Doha British School, Doha, Qatar. ${ }^{5}$ Cairo University, Giza, Egypt.
\end{abstract}

\section{Author contributions}

AO: concept, writing, and submission; DI: revision and editing; MA: critical revision.

\section{Declarations}

Conflicts of interest

On behalf of all the authors, the corresponding author states that there is no conflict of interest.

\section{Publisher's Note}

Springer Nature remains neutral with regard to jurisdictional claims in published maps and institutional affiliations.

Received: 6 September 2021 Accepted: 28 October 2021

Published: 6 November 2021

References

1. Lai J, Ma S, Wang Y, Cai Z, Hu J, Wei N, Wu J, Du H, Chen T, Li R, Tan H, Kang L, Yao L, Huang M, Wang H, Wang G, Liu Z, Hu S (2020) Factors associated with mental health outcomes among health care workers exposed to coronavirus disease. JAMA Netw Open 3(3):e203976. https://doi.org/10. 1001/jamanetworkopen.2020.3976

2. Horton R (2020) Offline: COVID-19-a reckoning. Lancet 395(10228):935. https://doi.org/10.1016/s0140-6736(20)30669-3

3. Doherty AM, Colleran GC, Durcan L, Irvine AD, Barrett E (2021) A pilot study of burnout and long covid in senior specialist doctors. Ir J Med Sci 13:1-5. https://doi.org/10.1007/s11845-021-02594-3

4. Panagioti M, Panagopoulou E, Bower P, Lewith G, Kontopantelis E, Chew-Graham C, Dawson S, van Marwijk H, Geraghty K, Esmail A (2017) Controlled interventions to reduce burnout in physicians: a systematic review and meta-analysis. JAMA Intern Med 177(2):195-205. https://doi. org/10.1001/jamainternmed.2016.7674

5. Schittek GA, Bornemann-Cimenti H, Sandner-Kiesling A (2021) Wellbeing of ICU patients with COVID-19. Intensive Crit Care Nurs 65:103050. https://doi.org/10.1016/j.iccn.2021.103050 